\title{
PENGARUH KUALITAS KEHIDUPAN KERJA TERHADAP MINAT BERTAHAN KARYAWAN DENGAN KOMITMEN ORGANISASI SEBAGAI VARIABEL MEDIASI
}

\author{
Andreas Trimurni' ${ }^{1}$, Mei $\mathrm{Ie}^{2 *}$, Henny $^{3}$ \\ ${ }^{1}$ Jurusan Manajemen, Universitas Tarumanagara Jakarta \\ Email: andreas.115170420@stu.untar.ac.id \\ 2 Jurusan Manajemen, Universitas Tarumanagara Jakarta \\ Email:meii@fe.untar.ac.id \\ ${ }^{3}$ Jurusan Akuntansi, Universitas Tarumanagara Jakarta \\ Email: henny@fe.untar.ac.id \\ *penulis korespondensi
}

Masuk : 21-09-2021, revisi: 06-10-2021, diterima untuk diterbitkan : 10-10-2021

\begin{abstract}
ABSTRAK
Penelitian ini bertujuan untuk menganalisis pengaruh kualitas kehidupan kerja terhadap minat bertahan karyawan dengan menggunakan komitmen organisasi sebagai variabel mediasi. Sampel sebanyak 53 karyawan PT XYZ di Tangerang, dengan teknik purposive sampling. Hasil penelitian menunjukkan bahwa pengaruh kualitas kehidupan kerja terhadap komitmen organisasi, pengaruh komitmen organisasi terhadap minat bertahan, pengaruh kualitas kehidupan kerja terhadap minat bertahan, pengaruh kualitas kehidupan kerja terhadap minat bertahan yang dimediasi komitmen organisasi, adalah positif dan signifikan. Penelitian ini menyarankan agar perusahaan mengevaluasi peraturan kerja, menjaga kondusifitas ruang kerja, menekankan norma dan aturan perusahaan kepada karyawan baru, membangun dan membentuk karyawan dengan pelatihan, serta menyediakan fasilitas kerja yang memadai dalam rangka meningkatkan kualitas kehidupan kerja serta komitmen organisasional. Hal tersebut pada akhirnya dapat meningkatkan minat bertahan karyawan dalam perusahaan.
\end{abstract}

Kata Kunci: kualitas kehidupan kerja, minat bertahan, komitmen organisasi.

\section{ABSTRACT}

The study aims to analyze the effect of quality of work life on employees' intention to stay by using organizational commitment as a mediation variable. Sampled as many as 53 employees of PT XYZ in Tangerang, with purposive sampling technique. The results showed that the influence of quality of work life on organizational commitment, the influence of organizational commitment to intention to stay, the influence of quality of work life on intention to stay, the influence of quality of work life on the intention to stay mediated by organizational commitment, was positive and significant. This research recommends that companies evaluate work regulations, maintain workspace conduciveness, emphasize company norms and rules to new employees, build and shape employees with training, and provide adequate work facilities in order to improve the quality of work life and organizational commitment. This can ultimately increase the employee's enduring interest in the company.

Keywords: quality of worklife, intention to stay, organizational commitment.

\section{PENDAhUluAN \\ Latar Belakang}

Sumber daya manusia adalah aspek penting dalam sebuah perusahaan. Hal ini dikarenakan sumber daya manusia menjadi penggerak dalam kegiatan operasional perusahaan. Namun, kesetiaan karyawan di perusahaan masih menjadi tugas berat yang belum terselesaikan. Ketika karyawan dilibatkan aktif dalam pengambilan keputusan perusahaan, tingkat absensi menurun, komitmen menjadi lebih besar, kinerja meningkat, dan kepuasan kerja menjadi lebih besar (Purnomo, 2017). Hal tersebut pada akhirnya dapat membantu menngkatkan minat bertahan karyawan pada tempatnya bekerja. 
Pada dasarnya, untuk mempertahankan karyawan agar tidak keluar dari perusahaan, perlu dilakukan penelitian untuk mengetahui hal-hal yang bisa mempertahankan karyawan dan membuat karyawan berminat untuk tetap bekerja di perusahaan. Hal ini berarti, penelitian yang membahas mengenai minat bertahan masih sangat diperlukan. Kemie dan Purba (2019), menjelaskan bahwa minat bertahan merupakan sikap yang dimiliki oleh karyawan untuk merasa adanya keterikatan dan memilih bertahan pada tempat mereka bekerja, meskipun ada tawaran pekerjaan lain yang lebih menarik. Jika sebuah perusahaan mengetahui hal-hal yang dapat membuat karyawan bersedia untuk bertahan di perusahaan, maka tingkat turnover karyawan dapat ditekan dan dapat menyelesaikan masalah yang saat ini terjadi.

Oleh karena itu, penelitian ini dilaksanakan guna memberikan memberikan gambaran dan saran yang diharapkan dapat mengatasi masalah minat karyawan bertahan yang sangat rendah di PT XYZ.

Menurut Alrowwad et. al. (2019) komitmen organisasi didefinisikan sebagai suatau keadaaan secara psikologis yang membentuk hubungan antara karyawan dan organisasinya dan memungkinkan individu untuk membuat keputusan apakah mereka ingin terus bekerja untuk organisasi atau tidak. Dengan adanya komitmen terhadap pekerjaan dan organisasi, maka karyawan diharapkan dapat menunjukkan kesediaan untuk bekerja lebih keras dan memiliki hasrat yang lebih besar untuk memilih tetap bekerja dalam perusahaan. Komitmen organisasi berkaitan erat dengan minat karyawan untuk bertahan, karena dengan adanya komitmen, karyawan akan merasa ada tanggung jawab dan keterikatan secara psikologis dengan perusahaan dan membuat karyawan mau untuk bertahan di perusahaan. Karyawan yang memiliki komitmen terhadap perusahaan cenderung akan memikirkan apa yang telah diberikan perusahaan, dan alasan-alasan mengapa mereka harus bertahan di perusahaan. Oleh sebab itu, komitmen organisasi karyawan harus dibentuk oleh perusahaan karena pastinya, karyawan tidak mungkin akan berkomitmen jika perusahaan tidak membentuk komitmen itu sendiri.

Menurut Daniel (2019) mengemukakan bahwa kualitas kehidupan kerja adalah kualitas yang terlihat dari hubungan antara karyawan dengan lingkungan kerjanya, dengan pertimbangan dimensi manusia, teknis dan ekonomi. Perusahaan atau tempat kerja memberi kesempatan kepada pekerja untuk membuat keputusan tentang, desain tempat kerja, pekerjaan merek dan memastikan kehidupan kerja yang sesuai bagi karyawan. Saat kualitas lingkungan atau kehidupan dalam pekerjaan memiliki kualitas yang sesuai dengan harapan karyawan, maka karyawan akan merasa nyaman dalam bekerja karena mereka merasa segala aspek dalam lingkungan kerja mereka, baik terlihat maupun tidak terlihat, memenuhi harapan mereka dalam bekerja dan keadaan ini cenderung akan membuat karyawan betah dalam bekerja.

Perusahaan yang mampu menjaga minat karyawan untuk bertahan, cenderung akan lebih diminati oleh karyawan lain, memiliki reputasi yang lebih baik dan akan dipandang sebagai perusahaan yang bertanggung jawab.

\section{KAJIAN PUSTAKA \\ Definisi Variabel}

Menurut Yadav, et. al. (2019), definisi kualitas kehidupan kerja adalah derajat yang menjadi prasyarat kebahagiaan individu terpenuhi, misalnya, kebutuhan yang bersifat fundamental untuk membuat manusia ceria. Menurut Rostiana (2017), kualitas kehidupan kerja mengacu pada persepsi karyawan tentang kesejahteraan fisik serta psikologis di tempat kerja. 
Menurut Fakhri et. al (2020) indikator dari kualitas kehidupan kerja diantaranya lingkungan kerja, budaya organisasi dan hubungan kerja dengan atasan maupun rekan kerja. Selain itu, termasuk didalamnya adalah pelatihan dan pengembangan, pemberian kompensasi, ketersediaan fasilitas, kepuasan keamanan kerja bagi karyawan, otonomi dalam melaksanakan pekerjaan, dan kesesuaian sumber daya.

Komitmen organisasi menurut Metin dan Asli (2018) merupakan keterlibatan individu dalam organisasi tertentu serta kemauan individu tersebt untuk mengerahkan upaya untuk tetap berada dalam organisasi. Menurut Inanlou dan Ahn (2017) komitmen organisasi dapat diartikan sebagai suatu kemelekatan secara psikologis dari karyawan terhadap organisasi atau perusahaan tempatnya bekerja. Bienkowska \& Tworek (2020) menyatakan bahwa komitmen organisasi menggambarkan hubungan yang terjalin antara karyawan dengan pekerjaan yang dijalankannya, yang dianggap valid dan relevan untuk mempertahankan keanggotaannya dalam perusahaan atau organisasi.

Alrowwad et al. (2020) menyatakan bahwa indikator komitmen organisasi adalah komitmen yang bersifat afektif, komitmen yang bersifat berkelanjutan, dan komitmen yang bersifat normatif.

Minat bertahan menurut Shahid, et. al. (2018) dapat diartikan sebagai niat atau keinginan karyawan untuk tetap berada dalam hubungan kerja yang ada dengan pemberi kerja mereka, baik untuk saat ini maupun masa mendatang. Menurut Bell dan Sheridan (2020), minat bertahan didefinisikan sebagai kemungkinan pilihan karyawan untuk tetap bertahan dalam pekerjaan maupun organisasinya dibandingkan dengan pilihannya keluar meninggalkan organisasinya untuk mencari pekerjaan lain. Presbitero dan Teng-Calleja (2019) menyatakan definisi yang kurang lebih sama, yaitu minat bertahan berarti kemauan karyawan untuk bertahan pada organisasi mereka.

Youcef et al (2016) menyatakan bahwa indikator dalam minat bertahan adalah berencana untuk tetap bertahan, tidak ada alasan untuk pindah, menolak untuk pindah, dan berencana untuk bertahan selama mampu.

Kualitas kehidupan kerja mengacu pada persepsi karyawan tentang kesejahteraan fisik serta psikologis di tempat kerja. Perusahaan atau tempat kerja memberi kesempatan kepada pekerja untuk membuat keputusan tentang desain tempat kerja, pekerjaan merek dan memastikan kehidupan kerja yang sesuai bagi karyawan. Saat kualitas lingkungan atau kehidupan dalam pekerjaan memiliki kualitas yang sesuai dengan harapan karyawan, maka karyawan akan merasa nyaman dalam bekerja karena mereka merasa segala aspek dalam lingkungan kerja mereka, baik terlihat maupun tidak terlihat, memenuhi harapan mereka dalam bekerja dan keadaan ini cenderung akan membuat karyawan betah dalam bekerja.

Saat kualitas kehidupan kerja meningkat, dan mampu meningkatkan komitmen organisasi, maka komitmen organisasi yang tinggi akan memunculkan sebuah minat dari karyawan untuk ingin bertahan di sebuah perusahaan dan akan meningkatkan minat bertahan dari karyawan itu sendiri. Melihat dari keterkaitan tersebut, maka model penelitian ini adalah sebagai berikut: 


\section{Hipotesis}

Gambar 1. Model Penelitian

H1: Kualitas kehidupan kerja berpengaruh positif terhadap komitmen organisasi.

H2: Komitmen organisasi berpengaruh positif terhadap minat bertahan karyawan.

H3: Kualitas kehidupan kerja berpengaruh positif terhadap minat bertahan karyawan.

H4: Komitmen organisasi memediasi pengaruh kualitas kehidupan kerja terhadap minat bertahan karyawan adalah signifikan dan bersifat positif.

\section{METODE PENELITIAN}

Penelitian menggunakan desain kuantitatif dengan metode non-probability sampling dengan pendekatan purposive sampling dalam pengambilan sampel sebanyak 53 orang karyawan PT XYZ. Kriteria sampel adalah masa kerja minimal 1 tahun. Pengumpulan data dalam penelitian ini menggunakan kuesioner.

Tabel 1. Indikator Pengukuran Variabel

\begin{tabular}{|c|c|}
\hline Variabel & Indikator \\
\hline \multirow{4}{*}{$\begin{array}{c}\text { Minat Bertahan } \\
\text { (Youcef et al., 2016) }\end{array}$} & 1. Berencana untuk tetap bertahan \\
\hline & 2. Tidak ada alasan untuk pindah \\
\hline & 3. Menolak untuk pindah \\
\hline & $\begin{array}{l}\text { 4. Berencana untuk bertahan } \\
\text { selama mungkin }\end{array}$ \\
\hline \multirow{20}{*}{$\begin{array}{l}\text { Kualitas Kehidupan Kerja } \\
\quad \text { (Fakhri et. al., 2020) }\end{array}$} & 1. Stres atas peran \\
\hline & 2. Pengawasan \\
\hline & 3. Karakteristik struktur \\
\hline & 4. Nilai organisasi \\
\hline & 5. Visi \\
\hline & 6. Norma yang berlaku \\
\hline & 7. Keputusan di tempat kerja \\
\hline & 8. Konflik \\
\hline & 9. Penyelesaian masalah \\
\hline & 10. Peningkatan efisiensi \\
\hline & 11. Peningkatan efektifitas \\
\hline & 12. Jam kerja \\
\hline & 13. Upah merata \\
\hline & 14. Kesempatan yang sama \\
\hline & 15. Keamanan \\
\hline & 16. Kepuasan karyawan \\
\hline & 17. Keamanan masa depan \\
\hline & 18. Koordinasi \\
\hline & 19. Hirarki \\
\hline & 20. Kecukupan sumber daya \\
\hline \multirow{2}{*}{$\begin{array}{c}\text { Komitmen Organisasi } \\
\text { (Alrowwad et al., 2019) }\end{array}$} & 1. Merasa dihargai \\
\hline & 2. Merasa diperlakukan adil \\
\hline
\end{tabular}




\begin{tabular}{ll}
\hline 3. Merasa didukung \\
\cline { 2 - 2 } 4. Gaji dan tunjangan \\
5. Rencana pensiun \\
6. Keterampilan \\
7. Hubungan sosial \\
8. Peluang yang hilang \\
\hline 9. Manfaat \\
10. Itikad baik \\
11. Kontrak kerja \\
\hline
\end{tabular}

Untuk uji validitas, menggunakan metode outer model pada partial least square. Pengujian validitas dan reliabilitas menggunakann nilai factor loading yang dianggap cukup baik berkisar 0,5 sampai 0,60, nilai AVE lebih besar 0,50 (Ghozali, 2016). Uji reliabilitas menggunakan nilai dari Cronbach's Alpha dan Composite Reliability, dengan angka Cronbach's Alpha > 0,5 dan Composite Reliability > 0,6.

Pengujian hipotesis dilakukan dengan melihat nilai $p$-value yang terdapat pada analisis jalur antar variabel (path analysis) dengan ukuran $p$ values $<\alpha$, maka hipotesis tidak ditolak jika $p$ values $<0,05$.

\section{HASIL DAN PEMBAHASAN}

\section{A. Hasil Uji Validitas dan Reliabilitas}

Adapun hasil uji validitas dan reliabilitas konstruk adalah:

Tabel 2. Hasil Uji Validitas dan Reliabilitas

\begin{tabular}{cccc}
\hline Variabel & $\begin{array}{c}\text { Cronbach's } \\
\text { Alpha }\end{array}$ & $\begin{array}{l}\text { Composite } \\
\text { Realibility }\end{array}$ & AVE \\
\hline Kualitas kehidupan kerja & 0,934 & 0,944 & 0,627 \\
\hline Komitmen Organisasi & 0,927 & 0,939 & 0,634 \\
\hline Minat Bertahan & 0,869 & 0,910 & 0,718 \\
\hline
\end{tabular}

Dari tabel 2 tersebut, terlihat bahwa terlihat bahwa nilai Cronbach's Alpha dari setiap variabel lebih dari 0.6 sehingga dapat disimpulkan bahwa variabel-variabel telah memenuhi persyaratan untuk dinyatakan reliabel. Demikian pula nilai Composite Reliability nilainya lebih dari 0.6, sehingga variabel-variabel tersebut telah memenuhi persyaratan.

Nilai AVE dari seluruh variabel juga telah memenuhi persyaratan, yaitu di atas 0,5 , sehingga semua variabel telah memenuhi persyaratan untuk dinyatakan valid.

Tabel 3. Analisis Validitas Diskriminan

\begin{tabular}{cccc}
\hline & Minat Bertahan & Kualitas kehidupan kerja & Komitmen Organisasi \\
\hline ITS1 & $\mathbf{0 , 8 7 9}$ & 0,779 & 0,777 \\
\hline ITS2 & $\mathbf{0 , 8 2 3}$ & 0,796 & 0,806 \\
\hline ITS3 & $\mathbf{0 , 8 0 9}$ & 0,720 & 0,642 \\
\hline ITS4 & $\mathbf{0 , 8 7 5}$ & 0,709 & 0,769 \\
\hline KO1 & 0,760 & 0,703 & $\mathbf{0 , 8 0 6}$ \\
\hline KO11 & 0,771 & 0,705 & $\mathbf{0 , 8 0 9}$ \\
\hline KO2 & 0,720 & 0,805 & $\mathbf{0 , 7 9 6}$ \\
\hline KO3 & 0,661 & 0,720 & $\mathbf{0 , 7 1 5}$ \\
\hline KO4 & 0,722 & 0,669 & $\mathbf{0 , 8 2 2}$ \\
\hline KO5 & 0,565 & 0,678 & $\mathbf{0 , 7 3 1}$ \\
\hline
\end{tabular}


PENGARUH KUALITAS KEHIDUPAN KERJA TERHADAP MINAT BERTAHAN Andreas Trimurni et. al. KARYAWAN DENGAN KOMITMEN ORGANISASI SEBAGAI VARIABEL MEDIASI

\begin{tabular}{cccc}
\hline KO6 & 0,716 & 0,623 & $\mathbf{0 , 8 0 7}$ \\
\hline KO7 & 0,734 & 0,743 & $\mathbf{0 , 8 3 0}$ \\
\hline KO9 & 0,686 & 0,747 & $\mathbf{0 , 8 4 0}$ \\
\hline QOW1 & 0,645 & $\mathbf{0 , 7 6 8}$ & 0,639 \\
\hline QOW10 & 0.715 & $\mathbf{0 , 8 2 5}$ & 0,680 \\
\hline QOW14 & 0,645 & $\mathbf{0 , 7 7 4}$ & 0,700 \\
\hline QOW16 & 0,619 & $\mathbf{0 , 7 9 8}$ & 0,754 \\
\hline QOW18 & 0,767 & $\mathbf{0 , 8 3 0}$ & 0.768 \\
\hline QOW19 & 0,668 & $\mathbf{0 , 7 4 8}$ & 0,673 \\
\hline QOW2 & 0,768 & $\mathbf{0 , 7 7 0}$ & 0,737 \\
\hline QOW3 & 0,691 & $\mathbf{0 , 8 5 0}$ & 0,723 \\
\hline QOW4 & 0,777 & $\mathbf{0 , 7 6 1}$ & 0,716 \\
\hline QOW6 & 0,715 & $\mathbf{0 , 7 8 8}$ & 0,676 \\
\hline
\end{tabular}

Dari tabel 3 , terlihat bahwa outer loading nilainya lebih dari 0,5 , maka semua indikator telah memenuhi syarat validitas.

\section{B. Hasil Analisis Data}

\section{Path Coefficients}

Path coefficients menganalisis besar pengaruh dari variabel bebas terhadap variabel terikat. Jika nilai path coefficients positif, artinya variabel independent diyakini memiliki pengaruh yang bersifat satu arah terhadap variabel dependen, sedangkan jika path coefficients negatif, artinya variabel independent diyakini memiliki pengaruh yang bersifat berlawanan arah dengan variabel dependen.

Tabel 2. Path Coefficients

\begin{tabular}{cc}
\hline Kualitas kehidupan kerja $->$ Komitmen Organisasi & 0.894 \\
\hline Komitmen Organisasi-> Minat bertahan & 0.464 \\
\hline Kualitas kehidupan kerja $\rightarrow>$ Minat bertahan & 0.474 \\
\hline Kualitas kehidupan kerja -> Komitmen Organisasi -> Minat bertahan & 0.415 \\
\hline
\end{tabular}

\section{2. $\quad$ Normed Fit Index (NFI)}

Nilai NFI $=0.630$ yang berarti nilai NFI tersebut berada pada rentang 0 sampai 1 yang dapat disimpulkan memenuhi kriteria NFI, yang berarti model yang diajukan sudah sesuai dengan model null atau tidak terjadi permasalahan dalam pembentukan model.

Tabel 3. Normed Fit Index (NFI)

\section{Q-Square}

\begin{tabular}{|c|c|} 
NFI & 0.630 \\
\hline
\end{tabular}

Nilai $Q$ Square dengan variabel terikat yaitu minat bertahan $=0.575$ dan nilai $Q$ Square dengan variabel terikat yaitu komitmen organisasi $=0.497$ yang berarti nilai $Q$ Square tersebut berada di atas nilai 0 , sehingga model penelitian yang terbentuk telah memenuhi persyaratan dari $Q$ Square, yang berarti nilai observasi yang dihasilkan oleh model dan estimasi parameternya dapat dikategorikan baik.

Tabel 4. Q-Square

\begin{tabular}{|c|c|}
\hline Minat Bertahan & 0.575 \\
\hline Komitmen organisasi & 0.497 \\
\hline
\end{tabular}




\section{F-Square}

Nilai $F$ Square kualitas kehidupan kerja terhadap minat bertahan $=0.268$ yang berada di atas 0.15 yang berarti $F$ Square antara kualitas kehidupan kerja terhadap minat bertahan dikategorikan sedang. Nilai $F$ Square kualitas kehidupan kerja terhadap komitmen organisasi $=$ 4.003 yang berada di atas 0.35 yang berarti $F$ Square antara kualitas kehidupan kerja terhadap komitmen organisasi dikategorikan kuat. Nilai $F$ Square komitmen organisasi terhadap minat bertahan $=0.256$ yang berada di atas 0.15 dan di bawah 0.35 yang berarti $F$ Square antara komitmen organisasi terhadap minat bertahan dikategorikan sedang.

Tabel 5. F-Square

\begin{tabular}{cl}
\hline Kualitas Kehidupan Kerja - Minat Bertahan & 0.268 \\
\hline Kualitas Kehidupan Kerja - Komitmen organisasi & 4.003 \\
\hline Komitmen organisasi - Minat Bertahan & 0.256 \\
\hline
\end{tabular}

\section{Uji Hipotesis}

Tabel 6. Uji Hipotesis

\begin{tabular}{cccc}
\hline Konstruk & T Statistics & P Value & Kesimpulan \\
\hline Kualitas Kehidupan Kerja -> Komitmen Organisasi & 24.194 & 0.000 & Tidak ditolak \\
\hline Komitmen Organisasi -> Minat Bertahan & 3.465 & 0.001 & Tidak ditolak \\
\hline Kualitas Kehidupan Kerja -> Minat Bertahan & 3.467 & 0.001 & Tidak ditolak \\
\hline $\begin{array}{c}\text { Kualitas Kehidupan Kerja -> Komitmen Organisasi -> } \\
\text { Minat Bekerja }\end{array}$ & 3.422 & 0.001 & Tidak ditolak \\
\hline
\end{tabular}

\section{Pembahasan}

Pada uji hipotesis 1, terlihat bahwa nilai t-statistic sebesar 24,194 dan juga $p$ values sebesar 0,000, sehingga hipotesis 1 tidak ditolak, yang berarti kualitas kehidupan kerja mempengaruhi komitmen organisasi dengan signifikan dan bersifat positif. Kualitas kehidupan kerja mengacu pada persepsi karyawan tentang kesejahteraan fisik serta psikologis di tempat kerja. Perusahaan atau tempat kerja memberi kesempatan kepada pekerja untuk membuat keputusan tentang, desain tempat kerja, pekerjaan merek dan memastikan kehidupan kerja yang sesuai bagi karyawan.

Menurut penelitian yang dijalankan oleh Waribo, et al, (2019), Yadav, et al, (2019), Sahni, (2019) saat karyawan merasakan kehidupan kerja atau atmosfir kerja yang berkualitas baik, karyawan cenderung akan lebih memiliki rasa ingin terikat dengan perusahaan karena karyawan merasa perusahaan memiliki kemauan untuk memperhatikan perasaan karyawan. Oleh karena itu, semakin baik kualitas kehidupan kerja, maka akan semakin tinggi juga komitmen organisasi yang dimiliki karyawan.

Pada uji hipotesis 2 diketahui bahwa nilai t-statistic sebesar 3.465 dan juga $p$ values sebesar 0,001, sehingga hipotesis 2 tidak ditolak, yang berarti komitmen organisasi mempengaruhi minat bertahan karyawan dengan signifikan dan bersifat positif.

Menurut penelitian yang dijalankan oleh Agus dan Selvaraj (2020), Youcef, et al. (2016), dan Phuong dan Trang (2017) dijelaskan keterkaitan antara komitmen organisasi dengan minat bertahan karyawan, yaitu saat karyawan memiliki komitmen yang tinggi terhadap perusahaan, maka karyawan cenderung memiliki tanggung jawab yang tinggi terhadap perusahaan itu sendiri. Dengan komitmen yang tinggi, karyawan cenderung merasa berkewajiban untuk bertahan di perusahaan. 
Pada uji hipotesis 3 diketahui bahwa nilai $t$-statistic sebesar 3.467 dan juga $p$ values sebesar 0,001, sehingga hipotesis 3 tidak ditolak, yang berarti kualitas kehidupan kerja mempengaruhi minat bertahan karyawan dengan signifikan dan bersifat positif.

Menurut penelitian yang dijalankan oleh Astrianti et al. (2020), dan Rostiana (2017) dijelaskan bahwa semakin meningkatnya kualitas kehidupan kerja yang dirasakan oleh karyawan di sebuah perusahaan, maka karyawan tersebut cenderung merasa emakin nyaman dalam bekerja dan dapat meningkatkan kesetiaannya terhadap perusahaan mereka. Mereka menyadari bahwa jika berpindah ke perusahaan lain, akan muncul risiko bahwa ia tidak akan mendapatkan kualitas kehidupan kerja yang sama dengan perusahaan saat ini. Oleh karena itu, dengan semakin kualitas kehidupan kerja, maka akan minat bertahan karyawan pun dapat lebih ditingkatkan.

Pada uji hipotesis 4 diketahui bahwa bahwa nilai t-statistic sebesar 3.422 dan juga $p$ values sebesar 0,001, sehingga hipotesis 4 tidak ditolak, yang berarti komitmen organisasi memediasi pengaruh kualitas kehidupan kerja terhadap minat bertahan karyawan

Minat bertahan dapat diartikan sebagai niat karyawan untuk tetap dalam hubungan kerja yang ada dengan pemberi kerja mereka saat ini untuk jangka panjang. Penelitian yang dijalankan oleh Agus dan Selvaraj (2020) menjelaskan bahwa karyawan yang merasakan adanya kualitas kehidupan kerja yang baik, akan cenderung lebih berkomitmen dalam bekerja dengan perusahaan karena karyawan akan lebih merasa diperhatikan, sehingga biasanya timbul suatu tanggung jawab agar karyawan tersebut bertahan di perusahaan yang telah memperhatikan kebutuhan mereka. Dengan komitmen yang tinggi, karyawan cenderung merasa adanya rasa memiliki dan merasa kewajiban untuk mempertahankan keanggotaannya di sebuah perusahaan. Keadaan ini secara langsung akan membuat karyawan lebih berminat untuk tetap bertahan di perusahaan.

\section{KESIMPULAN DAN SARAN}

Kesimpulan yang dapat dikemukakan sebagai berikut:

a. Kualitas kehidupan kerja mempengaruhi komitmen organisasi dengan signifikan dan bersifat positif.

b. Komitmen organisasi mempengaruhi minat bertahan dengan signifikan dan bersifat positif.

c. Kualitas kehidupan kerja mempengaruhi minat bertahan dengan signifikan dan bersifat positif.

d. Komitmen organisasi memediasi pengaruh kualitas kehidupan kerja terhadap minat bertahan.

Berdasarkan hasil penelitian, beberapa saran atau masukan yang sekiranya dapat digunakan atau bermanfaat bagi perusahaan maupun kepada penelitian selanjutnya, sebagai berikut:

a. PT XYZ dapat mengevaluasi kembali kualitas kehidupan kerja yang saat ini diterapkan dengan cara memperhatikan dan membuat aturan untuk menjaga kondusifitas ruang kerja, menekankan norma dan aturan perusahaan kepada karyawan baru, membangun dan membentuk karyawan dengan pelatihan, serta menyediakan fasilitas kerja yang memadai. Dengan hal ini diharapkan dapat meningkatkan komitmen karyawan dan meningkatkan minat karyawan untuk bertahan bekerja di PT XYZ

b. Untuk penelitian selanjutnya, dapat diperluas pada skala industrial dan dapat meneliti lebih tajam pada beberapa faktor seperti meneliti pada generasi millenial, generasi $X$ atau generasi baby boomer pada sebuah perusahaan untuk melihat perbedaan hasil penelitian. 


\section{REFERENSI}

Agus, A., \& Selvaraj, R. (2020). The mediating role of employee commitment in the relationship between quality of work life and the intention to stay. Employee Relations. 42(6). 12311248. https://doi.org/10.1108/ER-07-2019-0292

Alrowwad, A., Masadeh, R., Almajali, D., \& Obeidat, B. (2019). The role of organizational commitment in enhancing organizational effectiveness. Education Excellence and Innovation Management through Vision 2020. 9133-9154

Astrianti, A, N, M., \& Sartono, B. (2020). Quality of work life, organizational commitment and turnover intention in account officer of micro finance company. Sosiohumaniora - Jurnal $\begin{array}{llll}\text { Ilmu-ilmu Sosial dan } & \text { Humaniora. }\end{array}$ https://doi.org/10.24198/sosiohumaniora.v22i1.23121

Bell, M., \& Sheridan, A. (2020). How organisational commitment influences nurses' intention to stay in nursing throughout their career. International Journal of Nursing Studies Advances. 2(2020). 1-12. https://doi.org/10.1016/j.ijnsa.2020.100007

Bie'nkowska, A. \& Tworek, K. (2020). Job performance model based on employees' dynamic capabilities (EDC). Sustainability. 12(6):2250. 1-25. https://doi.org/10.3390/su12062250

Daniel, C. O. (2019). Analysis of Quality Work Life on Employees Performance. International Journal of Business and Management Invention. International Journal of Business and Management Invention (IJBMI). 8(02), 60-65.

Fakhri, M., Nurnida, I., Winarno, A., Kurnia, B., \& Suryana, D. (2020). Characteristics of quality of work life on employees at consultant company in Indonesia. Journal of Asian $\begin{array}{llll}\text { Finance, } \quad \text { Economics } & \text { 1105-1111. }\end{array}$ https://doi.org/10.13106/jafeb.2020.vol7.no11.1105

Ghozali, I. (2016). Konsep, teknik, dan aplikasi menggunakan Program SMARTPLS 3.0. Semarang: Univ Diponegoro.

Inanlou, Z., \& Ahn, Ji-Young. (2017). The effect of organizational culture on employee commitment: a mediating role of human resource development in Korean firms. The Journal of Applied Business Research. 33(1). 87-94. https://doi.org/10.19030/jabr.v33i1.9869

Metin, K., \& Asli, K. (2018). The relationship between organizational commitment and work performance: a case of industrial enterprises. Journal of Economic and Social Development (JESD). 5(1). 46-50.

Phuong, N, D, N., \& Trang, T, H, L. (2017). Factors affecting employee's intention to stay through organizational commitment: evidence from big-four auditing firms in Vietnam. Proceedings of the Annual Vietnam Academic Research Conference on Global Business, Economics, Finance \& Management Sciences. 767. 18-19. ISBN: 978-1-943579-61-7

Presbitero, A., \& Teng-Calleja, M. (2019). Employee intention to stay in an organization: examining the role of calling and perceived supervisor support through the theoretical lens of work as calling. Journal of Career Assessment. 28(2). 1-17. https://doi.org/10.1177/1069072719858389

Purnomo, A. K. (2017). Peran highperformance human resource management dalam upaya peningkatan kepuasan kerja karyawan CV Putra Sala Group. Jurnal Muara Ilmu Ekonomi dan Bisnis, 1(2), 46-56.

Rostiana, R. (2017). The quality of work life influence to turnover intention with personorganization fit and organizational commitment as mediators. Int. Journal of Economics and Management. 11(S1). 45-57.

Sahni, J. (2019). Role of quality of work life in determining employee engagement and organizational commitment in Telecom Industry. International Journal for Quality Research. 13(2). 285-300. https://doi.org/10.24874/IJQR13.02-03 
Shahid, A. (2018). Employee intention to stay: an environment based on trust and motivation. Journal of Management Research. 10(4). 59-71. https://doi.org/10.5296/jmr.v10i4.13680

Waribo, Y. J., Osibanjo, A., Akintayo, D, I., Adeniji, A, A., \& Fadeyi, O, I. (2019). The effect of quality of work life on employees' commitment across nigerian tech start-ups. International Journal of Mechanical Engineering and Technology. 10(3). 41-59. https://ssrn.com/abstract=3451664

Yadav, R., Khanna, A., \& Panday, P. (2019). An analytical study of quality of work life \& organizational commitment and their relation with revenue per employee of major IT companies in India. Journal of Human Resource and Sustainability Studies. 7(1). 284-301. https://doi.org/10.4236/jhrss.2019.72018

Youcef, S. , Ahmed, S, S. \& Boussahmine A. (2016). The impact of job satisfaction on turnover intention by the existence of organizational commitment, and intent to stay as intermediates variables using approach pls in sample worker department of transport saida, Management. (6)6. 198-202. http://doi.org/10.5923/j.mm.20160606.03 